\title{
2010 年以来英国城市更新政策革新与实践
}

The Reform and Practice of Urban Renewal Policies in the UK Since 2010

摘要: 面对国民经济衰退的现实情境, 英国政府自 2010 年以来改革 了原有的城市更新政策, 以期通过更新促进经济发展。本文从政策 整体制定及其实践检验的角度，阐述英国联合政府为应对原有城市 更新政策目标不清、不可持续等挑战, 采取了一系列更新政策革新 举措：地方企业合作组织及其区划、城市交易、区域发展基金、邻 里更新等; 并分析其政策的实效性、存在的问题以及相应的政策调整。 跟进英国城市更新政策革新及其实践, 有助于我们理解英国城市更 新政策的最新发展, 也将为我国存量规划的相关研究提供借鉴。

Abstract: Facing with the reality of national economic recession, the British coalition government reforms the original urban renewal policies to boost the economy since 2010. From the perspective of policy and its practice, this paper expounds a series of new policy innovation initiatives taken on by the British coalition government in response to the unclear, unsustainable objectives and other challenges of the original urban renewal policies, such as Local Enterprise Partnerships and Enterprise Zones, City Deals, the Regional Growth Fund, the Neighbourhood Planning and other social welfare policies. Then, it analysises the effectiveness, issues and adjustments of these policies. The research on the reform and practice of British urban renewal policies can help to understand the latest development in the UK, and to provide references to the redevelopment planning in China.

关键词：英国城市更新政策；政策革新；更新实践

Keywords: Urban Renewal Policies of the UK; Policy Reform; Practice of Urban Renewal Policies

国家社会科学基金重大项目 “基于智慧技术的滨海大城市安全策略 与综合防灾措施研究” (13\&ZD162), 天津市自然科学基金 “天津多模 式公共交通体系与上地利用开发的协同技术研究”(16JCQNJC07600)

作者: 刘晓逸, 天津大学建筑学院, 博士研究生。andycap@126.com 运迎霞, 天津大学建筑学院教授, 博士, 博士生导师, 城市规 划系主任。yunyx@126.com 任利剑 (通信作者), 天津大学建筑学院, 博士, 副研究员。 renlijian@126.com

\section{引言}

自 2008 年全球金融危机爆发以来, 英国地方经济普遍持 续衰退。为摆脱经济低迷和地方发展诉求的压力, 英国联合 政府自 2010 年成立以来, 启动了以地方主义 (Localism)、去 中心化 (Decentralisation)、大社会 (Big Society) 等为名的新 一轮政策改革议程, 于 2011 年颁布极具代表性的地方化法案 (Localism Act), 并进一步提出“以更新促进经济发展, 共享 发展成果” 的口号 ${ }^{[1]}$ 。本文对英国 2010 年以来主要的城市更新 政策创新探索及其实践成效展开分析, 以期对我国新型城镇化 下的存量规划编制及其实施提供借鉴。

\section{1 现有城市更新政策面临的困境和挑战}

既有的英国城市更新政策框架，是在由罗格斯 1999 年 提交的“走向城市复兴”报告的基础上发展完善的, 其主 要内容可分为城市复兴 (Urban Renaissance) 和街区更新 (Neighbourhood Renewal) 两个平行的政策体系。城市复兴 试图寻求全面的公民社会复兴战略, 强调城市设计引导在消 费和房地产经济与物质环境改善中的地位; 主要通过制定各 类更新计划, 成立相应的管理机构来实施 ${ }^{12183}$, 主要的政策类 型包括单一更新预算 (SRB: Single Regeneration Budget)、英 国合作社（EP: Eglish Partnerships）、区域发展机构（RDAS: Regional Development Agencies)、城市更新公司 (URCS: Urban Regeneration Companies)、住房市场更新先锋组织 (Housing Market Renewal Pathfinders) 等; 社区更新意在将资源分配 到衰败地区, 处理多方面的贫困（教育、住房、就业等） 问题, 改善其公共服务 ${ }^{[3]}$; 主要的政策类型包括邻里管理开 拓组织 (NMP: Neighbourhood Management Pathfinders)、社 区新协议 (NDC: The New Deal For Communities)、邻里 工作协助 (Working Neighbourhoods)、地方企业发展组织 
(Local Enterprise Growth Initiatives)、街区更新基金（NRF: Neighbourhood Renewal Fund) 等 ${ }^{[3] 92}$ 。

然而, 无论是在城市层面还是社区层面, 英国既有的城 市更新政策难以满足新的发展诉求, 面临诸多挑战。城市复 兴政策虽然对城市形象有一定的改善, 但是产生了诸如低端 商业、城市形象雷同等问题, 以房地产为导向的城市更新难 以为继 ${ }^{[2] 100}$; 该方面的更新政策目标和所要解决的城市社会 经济问题之间的联系不够明确 ${ }^{[4]}$; 过多关注城市物质环境, 而忽视了社会中作为个体的人的发展, 社会排斥问题仍然存 在 $^{\left.{ }^{5}\right]}$ 。事实表明, 在实施新工党城市更新政策期间, 城市之 间、城市内部以及区域之间的不平等在加剧, 不利于英国经 济的发展 ${ }^{[6]}$ 。从社区层面来看, 在布莱尔 “第三条道路” (The Third Way）理论哲学下的社区治理并没有有效地促进社区 参与更新, 因政府能够通过财政等措施控制参与社区更新中 的半官方机构组织, 反而导致了双方的紧张关系 ${ }^{[2]}$; 在缺少 社区充分参与更新的情况下, 类似于社区新协议 (NDCS)、 邻里工作协助等这类更新政策并没有解决社区参与更新受益 的实质性问题, 难以实施 ${ }^{[5]}$ 。新工党通过综合更新预算、城 市更新公司等基于区域行动（ABIS: area-based initiatives）的 更新方法, 因存在缺乏社区参与、过度依赖房地产促进更 新等诸多不足而饱受批评 ${ }^{[4,7]}$ 。社区和地方政府部 (DCLG: Department for Communities and Local Government) 在其 2009 年的分析报告中指出, 随着全球经济危机的爆发, 新 工党时期以房地产开发与以消费为导向的城市复兴已难以为 继 ${ }^{[8]}$ 。英国保守党对于新工党的城市更新政策批评则主要体 现在其智库交流报告中, 认为过去 50 年英国在城市更新上 的努力是失败的, 并非每个城市都能进行更新, 应将伦敦及 其南部地区作为未来更新的重点, 更新预算应当下放到社区 层面 ${ }^{[9]}$; 在其 2010 年竞选前进一步指出, 衰败社区和内城 应获得更新, 合作依然是城市更新的核心问题, 但中央政府 应当放宽对地方的管控, 相关的发展权利应当下放至地方社 区层面。

\section{2 城市更新政策新指引}

正如琼斯 (Jones) 和塔隆 (Tallon) 所说的那样, 政 府的执政理念与政策环境对更新政策的实施有着决定性的 影响 ${ }^{[2,10]}$ 。为推动更新政策创新, 2010 年成立的英国卡梅 伦政府通过颁布《地方化法案》(Localism Act 2011), 制 定《国家规划政策框架》(NPPF: National Planning Policy Framework), 提出去中心化 (Decentralisation)、大社会 (Big Society) 议程等一系列举措, 为此后的城市更新政策革新与 实践奠定了坚实的基础。地方化法案, 一方面取消了原新 工党时期的区域发展机构 (RDAS), 以地方企业合作组织
(LEPS: Local Enterprise Partnerships) 代之; 另一方面, 规 定相关的规划权利下放至社区层面, 确立了邻里规划 (The Neighbourhood Planning) 的相关自主决策权 ${ }^{[11]}$ 。在国家规 划政策框架层面, 将原有 1000 多页的政策文件精简到 50 页, 意在简化规划程序和放松规划管制 ${ }^{[12]}$ 。在大社会、地方 主义、去中心化等议程下, 英国卡梅伦政府对原主管城市更 新政策的相关部门进行职能调整, 于 2010 年末废止原内阁 办公室 (the Cabinet Office) 的社会排斥工作组 (the Social Exclusion Task Force), 并将其主要职能移交至公民社会办公 室（the Office for Civil Society）; 将原主管城市更新政策的 社区和地方政府部 (DCLG) 制定城市社会问题方面政策的 权利, 移交至社会工作和福利部门（the Department of Work and Pensions), 社区和地方政府部主要保留负责制定地方企 业合作组织 (Local Enterprise Partnerships) 篮选和企业区划 (Enterprise Zones) 两项主要的经济职能, 其他关于城市更 新项目制定和运作等的权利则交由财政部 (HM Treasury) 和商务创新技术部 (BIS: Department for Business Innovation $\&$ Skills）等部门, 或多部门联合处理。

英国政府通过法制化改革和部门重构等举措, 在延续其 原有的更新政策体系架构（即城市一社区两大平行体系）的 基础上, 其更新政策改革主要围绕 “更新推动经济增长, 参 与更新受益”这一政策目标展开 : 在城市层面主要强调放松 管制, 加强协作; 在社区层面则主要强调放权更新。由此, 英国以更新推动经济发展与参与更新受益为导向, 以“权利 下放”为核心, 面向 “地方企业发展”、“城市与区域协作”、 “社区自主更新”等政策的探索方兴未艾。

\section{3 实践与评价：更新政策的调整与完善}

\section{1 地方企业合作组织及其企业区划}

“更新推动经济发展” 首先体现在地方企业合作及其 企业区划制度上。2010 年设立的地方企业合作组织 (Local Enterprise Partnerships), 类似于新工党时期的区域发展机构 (RDAS), 享有优先安排地方经济发展项目的权利（优先安 排的项目可免去公共参与过程, 可通过开发咨询报告的形式 替代规划许可等), 主要负责刺激地方经济发展与创造就业岗 位, 其具体措施包括 : 一是建立商业部门和市民合作领导的 相关组织, 将部分发展的自主权下放至社区和商业部门;二 是营造良好的发展环境以及建立有效的激励制度 (incentives regime）; 三是致力于发展具有长期经济效益的产业, 引导 私人部门投资类似于能源、交通、旅游等产业 ${ }^{[13,14]}$ 。企业区 划 (Enterprise Zones), 与 20 世纪 80 年代的企业区 (Enterprise Zone）建设机制有相似之处, 即通过免税, 补贴、简化规划 管治等激励措施吸引企业; 其不同之处在于新的企业区划不 
再以土地出让作为主要收益来源, 而是通过 25 年或更长的 发展计划, 从企业业务增长中获得收益, 且高度重视本地制 造业的发展 ${ }^{[13]}$ 。企业区选址一般在城市范围内, 且位于有经 济增长潜力的区位, 其建设权主要通过竞标的形式获得, 规 模一般为 $50 \sim 150 \mathrm{hm}^{2}$ 。以伯明翰企业区为例, 为打造世界级 的城市中心, 伯明翰企业区由 7 个建筑组群组成, 散落在市 中心地区, 占地 $68 \mathrm{hm}^{2}$, 以商业、金融、医疗服务等高端生 产性服务业为主, 主要是通过税收优惠、补贴、简化规划管 制等方式吸引企业 ${ }^{[15,16]}$ 。

目前, 共建地方企业合作组织 39 个, 划定企业区 26 个, 其中已建企业区 18 个, 拟建 8 个 ${ }^{[17]}$ 。地方企业合作组织及 其企业区划制度在一定程度上防止类似于上世纪 80 年代企 业区更新建设存在的“就业替代”（job displacement）现象, 在发展本地产业、创造经济动力、㲠动私人投资、引导政府 有限资源向特定地区配置等方面具有明显的优势; 但在一定 程度上类似于 20 世纪 80 年代的企业区更新政策, 意味着企 业发展、房地产导向等更新理念的回归 ${ }^{[2]}$ 。此外, 财政部对 企业区有一定的控制权, 倾向于大型项目, 这在一定程度上 和地方的发展诉求存在冲突 ${ }^{[14]}$ 。地方企业合作组织及其企业 区更新创新主要体现在其激励治理方面, 在推动地方经济发 展、提高地方城市经济竞争力上不失为一种有效形式, 但其 长期的竞争力建立始终需要慎重权衡各方的利益问题, 基于 长远利益的企业区更新治理有待进一步的探索。

\section{2 城市交易}

2011 年的地方化法案引进《核心城市修正案》(The Core Cities Amendment), 英国联合政府通过在核心城市设 立城市政策股（The Cities Policy Unit）并进行城市交易（City Deals) 的形式来加强中央与地方城市之间的合作, 意在寻求 推动城市经济发展的新创意, 释放经济活力。所谓核心城市 是指在欧洲具有一定城市竞争力的城市, 享有一定的自主发 展权利, 包括伯明翰、利物浦、曼彻斯特、卡迪夫、谢菲尔 德等 10 个城市。城市政策股则由核心城市的地方政府、私 人部门等联合组成, 共同确定地方城市的经济发展战略并制 定相关的规划。城市交易是中央政府和城市之间的一个协 议。中央政府依据地方城市的实际发展需要, 提供不同的政 策工具下放相应的权利, 包括自主负责本地方的相关事务、 按照地方意愿发展经济、制定推动经济发展相关措施、对公 共财政的自由支配等; 每个城市交易中, 参与交易的城市都 应当明确其所在政策股的城市管治形式, 表达各自的需求并 给出相应的承诺, 如免税激励私人部门投资、有能力为交易 投人一定的资源、良好的公共财政支出控制等; 为加强地 方政府和本地经济发展的联系, 英国政府通过增长交易协
议（Growth Deals）的形式鼓励地方企业合作组织参与城市 交易, 每年可向地方企业合作组织提供约 120 亿英镑的地 区发展基金（Local Growth Fund） ${ }^{[18]}$ 。以谢菲尔德城市地区 (Sheffield City Region) 的城市交易为例。谢菲尔德城市地 区从联合政府获得 2700 万英镑的发展基金, 并承诺其有能 力吸引 4400 万英镑的私人开发投资, 创造 4300 个就业岗位, 改变其在高端制造业落后的局面; 其城市交易的内容包含了 城市区域的投资计划、城市地区的技术发展计划、交通改善 计划、核先进制造业支持声明, 以及相关的城市管治模式等 内容 ${ }^{[19]}$ 。

城市交易率先在英格兰地区进行实验。目前共进行了两 轮城市交易。2012 年的第一轮城市交易有谢菲尔德、利物 浦等在内的 8 座城市参加 ${ }^{[18]}$ 。2013 年的第二轮城市交易邀 请了包括剑桥、诺维奇等在内的 20 座城市。不同于 20 世纪 90 年代城市更新中的城市挑战（City Challenge）政策, 城市 交易的目标更为明确, 无论在其活动开展还是相关机构的组 织上更为灵活、多元, 尤其注重地方城市的发展, 充分考虑 地方发展的意愿; 不仅在协调城市发展关系, 中央和地方关 系等方面具有一定的灵活性和针对性, 在促进城市职能分工、 协调区域发展、落实国家发展战略等方面亦具有一定的创新 性。然而, 其具体的实施协调机制设计并不完善, 如城市之间、 城市实际决策和城市交易协议冲突的调解机制等方面, 尚未 做出明确的说明和相关的制度安排。

\section{3 区域发展基金}

为改善落后地区的经济环境状况，2010 年商务创新技 术部 (BIS) 与社区和地方政府部等联合制定以空间为导向 的区域发展基金 (RGF: Regional Growth Fund)，主要引导和 资助具有发展潜力和能创造长期就业的私营部门向那些过于 依赖公共部门就业的地区或社区投资。区域发展基金申请评 估条件包括：(1) 项目对公共服务的依赖程度, 私人部门发 展的潜力及其项目区位; (2) 项目能带来额外就业人数与就 业岗位类型; (3) 用量化的方法评估其经济及社会价值, 如 环境效益、培训和技术；(4) 符合相关法律的规定等 ${ }^{[20]}$ 。该 基金的用途一般分为四个方面：（1）用于协助企业发展, 如 创新、培训等；（2）向中介机构或贷款机构提供相关补贴, 如开展各类调查、研究所需费用等; (3) 用于土地整备以激 励商业和工业发展; (4) 其他支出, 如交通设施改善、旅游 宣传、防洪等 ${ }^{[21]}$ 。

该基金最初向所有部门和组织开放, 2013 年后仅向私人 部门和组织开放。目前, 该项基金总共进行了 6 轮申请 : 第 一轮共收到 464 份申请, 申请基金达 27.8 亿英镑, 仅 45 份 获批; 第二轮收到 492 份申请, 申请基金达 33 亿英镑, 仅 
119 份获批; 前四轮基金支出达 26 亿英镑, 共资助了 286 个 开发项目, 创造 28 万个就业岗位; 2013-2014 年进行了第 5 、 6 轮申请, 预计到 2017 年其基金支出达 32 亿英镑 ${ }^{[20 !}$ 。来自 商务创新技术部（BIS）最新的区域发展基金评估报告指出, 该项政策在一定程度上改善了区域发展不平等的状况，但在 申请条件设置，基金用途划分等方面还有待进一步完善 ${ }^{[21]}$ 。 财政激励作为调控更新规划实施的有效政策工具之一, 在加 快落后地区的项目落实，吸引相关投资流入特定的空间地区 方面具有优越性。在实际操作中, 英国在更新财政支出的用 途划分与申请内容评估管理等方面有一定的创新, 但是仍充 满挑战, 主要原因在于监督和检查地方更新财政支持申请及 其实施方面的交易成本太高, 容易因经济利益导致竞争申请 更新资金的无序局面。

\section{4 社区更新}

2010 年英国联合政府上台后的一项重要新政举措, 是 确立地方层面的邻里规划 (The Neighbourhood Planning), 赋权邻里组织参与地方发展。2011 年的《地方化法案》引 人邻里规划制度安排, 规定社区、第三方组织等在地方和社 区公共服务与开发建设方面拥有一定的自主决策权, 包括：

（1）社区建设挑战权：社区组织、地方政府职员、第三方 机构等, 如果他们认为自己具备提供更好服务的能力, 可通 过竞标获得全部或部分地方政府服务职能; (2) 邻里规划 权：允许各社区共同决定街区布局；（3）社区建设权：允许 社区提出地点具体的、小规模的、由社区主导的建设项目 ;

（4）社区土地再开发权 : 允许社区自行开发那些利用不充 分, 未被利用的公共土地 ${ }^{[11,22]}$ 。邻里规划的编制是自愿自发 的, 依据编制深度不同, 可分为三种: 一是邻里发展规划, 具体确定新建住房和办公建筑的具体位置、风格等; 二是邻 里发展条例, 对于满足相关条例的新开发项目授予规划许可, 不用再向地方规划当局申请规划许可; 三是社区建设权条例, 主要是针对具体地点的小规模自主建设 ${ }^{[23]}$ 。为确保邻里规划 与地方政府规划的发展战略意图相一致, 地方政府对社区更 新的邻里规划编制组织提供信息、资金和简单的指引，检查 其是否符合 2012 年颁布的《国家规划政策框架》及其他相 关的基本规定，负责组织对社区更新规划进行公民投票，以 确保社区的相关发展要求在规划中生效 ${ }^{[24]}$ 。与此同时, 为鼓 励各社区自主编制邻里更新规划, 《地方化法案》在社区更 新中引人基础设施税, 规定已编制邻里规划的社区居民可从 新的开发中获得 $25 \%$ 的社区基础设施税，未编制邻里规划 的则只能获得 $15 \%$ 。

然而，在放权地方发展的规划实践中，国家发展战略、 地方政府规划目标和邻里规划自主决策屡有冲突, 尤其在住
房建设方面。道斯 - 希尔 (Daws Hill) 在其邻里规划编制过 程中, 对威科姆 (Wycombe) 地方政府的发展意图经常采取 抵触性的做法, 而威科姆地方政府则利用其管治权将其邻里 规划的空间范围划定在政府发展意图的地区之外; 布莱顿霍 夫 (Brighton \& Hove) 的地方规划因其没有安排足够的居住 用地而被予以驳回并重新修订; 南剑桥 (South Cambridge) 地方政府因在其发展规划方案中, 将 9000 套新住房的大型 建设项目拟安排在沃特比奇 (Waterbeach) 社区边缘的大片 废弃军营而引发了强烈抗议 ${ }^{[26]}$ 。

针对各类规划中因权利界定不清导致的规划冲突问 题, 2016 年英国政府专门引进《住房规划法》(Housing and Planning Act), 对住房市场、邻里规划、地方规划等做出说 明 ${ }^{[27]}$ 。在同年的《邻里规划法案》(Neighbourhood Planning Bill) 中对具体的规划实施措施进行了详细的阐述, 社区和 地方政府部就邻里规划法案中的规划禁止行为做了进一步的 评估和案例跟踪研究, 提出相关的法案修正意见 ${ }^{[28]}$ 。《地方 化法案》下的社区更新意味着从政府全权管控、封闭运作的 传统更新模式, 转向地方社区自主发展主导的模式 ${ }^{[29]}$, 同时 国家亦可通过其他各种方式将其管治权利渗透到社区个人的 诸多方面 ${ }^{30 !}$ 。因此, 放松管治、权利下放体现了产权, 尤其 是物权是保障社区更新受益、公共参与、竞争参与更新的有 效途径, 亦体现了更新法制化对更新实施的重要性; 与此同 时, 由于其合作管治模式不明确、发展权利界定不清, 尤其 是规划涉及的相关建设行为权利界定不清, 不仅增加了地方 政府实施更新规划的难度, 而且降低资源配置的效率, 不利 于地方政府利用更新市场促进经济发展战略的实现。

\section{5 其他相关政策探索}

与城市更新紧密关联的其他政策改革, 是跨部门的, 以保障个人就业、生活等为目标的社会福利政策。20世纪 50-60 年代的福利国家建设旨在 “社会平均”。新时期的英 国联合政府, 正如前文所述, 通过部门重构, 将原社区和地 方政府部的部分城市更新职能移交至其他相关部门, 希望通 过整合相关的社会福利政策来整体解决城市更新中的社会排 斥、社会资本培育、公共品建设等问题。社区和地方政府部 联合交通部为地方企业合作组织成立了 7.3 亿英镑的增长地 区基金（Growing Places Fund）以资助企业区内的基础设施 建设 ${ }^{[31,32]}$ 。为解决社会对国家福利依赖、城市贫困和弱势群 体就业, 尤其是大龄劳动力就业等问题, 社会工作和福利部 与财政部将福利改革与就业政策结合, 针对不同的就业人群 制定不同的机制, 如青年合同、残疾人就业协助和老年人持 续就业协助等, 将这些内容整合到区域发展基金协议中, 并 纳人相应企业区划的企业就业合同条款 ${ }^{[33]}$ 。针对那些在公共 
服务开支过高、融人社区存在困难的家庭, 地方政府通过提 供公共服务就业、专门的咨询服务以及其他综合性的途径予 以协助, 并计划每 3 年提供 4.4 亿英镑的资金援助 ${ }^{[34]}$ 。虽然 城市更新部门的职能调整及其更新政策的社会福利化的整 体实效仍有待评估, 但从另一方面体现了权责分明、结构 合理的机构设置以及部门协作是赋权参与更新及其实施的 有力保障。

\section{4 结论与讨论}

英国政府的系统性政策革新, 将城市更新政策的发展 推向了一个新的历史时期。此次城市更新政策的改革, 英 国联合政府一方面主要通过更新企业区、促进城市交易、 协调区域发展等途径推动城市层面的经济发展, 尤其是本 地市场的发展; 另一方面则主要强调放权地方发展, 保障 社区更新权利, 非空间福利政策整合等实现社区更新受益, 体现的是一种赋权参与的思想。总体上体现了针固市场、 还权赋能的特质。英国城市更新政策革新收到了一定成效, 尤其是在促进本地市场竞争力发展方面, 但其更为深刻的 社会经济影响以及具体政策的最终效益仍有待进一步的评 估和观察, 如社区放权更新引发的冲突, 城市交易的具体 实施机制等 (表 1 )。

正如卡林沃思 (Cullingworth) 与纳丁 (Nadin) 所指出
的那样, 规划政策的制定与实施 (行动) 是分不开的; 英国 的城市规划为英国政府应对选举的意见提供了一条路径; 但 自 1992 年以来, 中央政府在其规划政策革新指引上倾向于 将规划政策、建议与社会需求、社会问题联系起来; 最新的 规划政策文件沿着这一思路走得更远；英国规划政策在 “市 场理性” 的经济体系内运作的同时又保持其自身的“自由裁 量” 特质, 但后者也在逐步走向产权明哳的规划政策指引, 城市规划成为协调利益冲突的重要机制 ${ }^{[35]}$ 。2010 年以来英 国的城市更新政策创新, 对城市更新这一极具社会经济综合 性、挑战性和前瞻性的理论与实际议题, 开展了国家层面的 实验。虽然英国进行更新政策创新有其特定的历史时空局限, 但其 “利用更新促进经济发展, 放权社区参与, 保障更新受 益”所体现的核心思想仍然是如何在市场经济体系内通过更 新规划来协调相关的利益冲突问题。

“让市场对资源配置起决定性作用” 是我国十八大以来 《中共中央关于全面深化改革若干重大问题的决定》中的 重要改革思路。产权交易是我国存量规划的核心 ${ }^{[36]}$, 存量 规划中的土地发展权重构涉及土地增值的利益协调问题 ${ }^{[37]}$ 。 因此，从“市场经济下的更新规划编制与实施” 的角度来 看, 英国更新政策革新目标, 实践过程中所暴露的问题及 其后续的修正与调整, 我国存量规划与实施可从以下几方 面进行经验借鉴。

\section{表 12010 年以来英国城市更新政策革新与实践}

\begin{tabular}{|c|c|c|c|}
\hline \multicolumn{2}{|c|}{ 社会政治经济背景 } & \multicolumn{2}{|c|}{$\begin{array}{l}2008 \text { 年全球经济危机导致地方经济发展普遍低迷, 加上结构性财政赤字, 英国联合政府启动了地方主义 (Localism)、去中心化 } \\
\text { (Decentralisation)、大社会 (Big Society) 等一系列改革议程 }\end{array}$} \\
\hline \multirow{4}{*}{$\begin{array}{l}\text { 原有更新政策 } \\
\text { 的主要问题 }\end{array}$} & \multirow[t]{2}{*}{ 城市层面 } & 主要政策 & $\begin{array}{l}\text { 综合更新预算（SRB: Single Regeneration Budget）、英国合作社（EP: Eglish Partnerships）、区域发展机构（RDAS: } \\
\text { Regional Development Agencies）、城市更新公司（URCS: Urban Regeneration Companies）、住房市场更新先锋组 } \\
\text { 织 (Housing Market Renewal Pathfinders）等 }\end{array}$ \\
\hline & & 问题所在 & $\begin{array}{l}\text { 城市复兴 (Renaissance) 过于依赖房地产开发与消费 ; 过于关注物质环境问题 ; 更新目标与社会经济、社会问 } \\
\text { 题缺乏紧密联系 ; 社会排斥问题仍然突出 ; 区域不平衡加剧 ; 不利于英国整体经济的持续发展 }\end{array}$ \\
\hline & \multirow[t]{2}{*}{ 社区层面 } & 主要政策 & $\begin{array}{l}\text { 邻里管理开拓组织（NMP: Neighbourhood Management Pathfinders）、社区新协议 (NDC: The New Deal For } \\
\text { Communities)、邻里工作协助（Working Neighbourhoods）、地方企业发展组织（Local Enterprise Growth } \\
\text { Initiatives）、街区更新基金（NRF: Neighbourhood Renewal Fund）等 }\end{array}$ \\
\hline & & 问题所在 & 相关政策并没有从实质上解决社区参与更新受益的问题，从而导致其政策难以实施、社会效益不明显等 \\
\hline \multicolumn{2}{|l|}{ 政策目标 } & \multicolumn{2}{|c|}{ 更新促进经济发展 ; 共同分享发展成果 } \\
\hline \multicolumn{2}{|l|}{ 更新指引 } & \multicolumn{2}{|c|}{$\begin{array}{l}\text { 《地方化法案》 (Localism Act 2011), 同年引进《核心城市修正案》 (The Core Cities Amendment 2011); 制定《国家规划政策框架》 } \\
\text { (NPPF: National Planning Policy Framework) ; 社区和地方政府部 (DCLG: Department for Communities and Local Government) 职 } \\
\text { 能调整等 ; 上述举措为城市更新政策革新与实践奠定了坚实的制度基础 }\end{array}$} \\
\hline \multirow[t]{2}{*}{ 政策革新 } & 城市层面 & 主要政策 & $\begin{array}{l}\text { 地方企业合作组织及其企业区划（Local Enterprise Partnerships and Enterprise Zones 2010）；城市交易（City } \\
\text { Deals）; 区域发展基金（RGF: Regional Growth Fund）; }\end{array}$ \\
\hline & 社区层面 & 主要政策 & 邻里规划（The Neighbourhood Planning）以及相关的社会福利政策改革 \\
\hline \multicolumn{2}{|l|}{ 政策实践效益 } & \multicolumn{2}{|c|}{$\begin{array}{l}\text { 新时期的英国城市更新政策由于实施时间较短, 还难以从整体上对其进行评述并得出确定性的结论, 尤其是全球经济危机对英 } \\
\text { 国经济发展的持续影响使其更新政策的调整还存在多种可能性 ; 但就目前政策实施的情况而言, 在初步实现其政策目标的同时 } \\
\text { 亦存在政策体系、实施机制有待完善, 新的利益冲突频发等问题 ; 新的政策也面临治理机制的战略选择问题 }\end{array}$} \\
\hline
\end{tabular}

资料来源：作者整理 
（1）更新规划理念、创新制度环境。制度环境或者如诺 斯所说的制度安排（如司法机构）对于存量规划的实施无疑 是重要的。正如英国地方化法案及其邻里规划等政策不断修 正与完善所展现的那样, 应适时更新规划理念, 通过法制、 机构改革等措施为存量规划的实施奠定良好的政策环境与强 有力的制度基础。

（2）以产权明晰为导向的更新规划编制。英国城市更新 政策革新在其实践过程中针对 “产权模糊性” 问题进行了有 益的探索, 如更新机构的职能重构、地方企业发展组织、城 市交易参与组织、社区参与更新组织治理以及更新财政用途 细分与更新基金申请内容评估等，但仍存在因 “模糊性产 权” 的制度安排导致的冲突与规划政策的调整问题, 如邻里 规划中的住房建设冲突。在市场经济自愿、公平等交易原则 下, 存量规划编制的首要挑战来自于其规划所划定的空间产 权是否 “清晰”。存量规划空间设计中的空间用途划分及其 指标的制定更多的是产权明晰的表达。存量规划的编制应当 围绕 “如何清晰的划定产权” 这一主题来构建其分析工具和 具体的实施策略。

（3）市场经济下的土地发展权管制问题。从英国土地发 展权的演变历史来看, 英国 1947 年《城乡规划法》(Town and Country Planning Act, 1947) 被认为是土地增值归公的 政策标志 ${ }^{[37]}$, 但仍没有上升至法律层面, 且其后来进行的多 次规划法修订也表明, 市场经济下政府对于土地发展权的管 制正逐步放宽 ${ }^{[35]}$ 。2011 年的《地方化法案》更是以法律的 形式将土地发展权的诸多权能下放，如特定条件下免去社区 更新规划许可申请、社区更新规划编制形式多样、社区居民 可自行决定社区更新内容等，确立了英国 “放权发展”的制 度安排, 明确了社区在土地再开发过程中的相关自主权利。 但在实际操作中，地方政府仍可通过相关的管制权利与相关 社区进行博弯, 进而产生了一定的冲突。其后的《住房规划 法》《邻里规划法案》等措施的颁布实则是一种竞争使用土 地资源规则的治理，通过不断明确各类建设行为边界的方式 来确保地方化法案相关目标的落实。可见, 要实现市场经济 下土地再开发的有序发展，在分权发展、土地发展权下放的 同时应加强土地相关产权的结构治理, 通过相关的法律法规 政策等逐步替代土地发展权管制制度。土地发展权管制并不 是市场经济下的唯一选择。

（4）非空间指向的社会福利政策整合对于存量规划实施 的重要性。英国更新政策的社会福利化体现在其更新综合性 的特点, 主要是通过财政机制、管控机制、部门重构与协作 等多种途径得以实现。市场是通过价格机制来影响交易的, 所谓价格是物品价值的比率。英国城市更新中的社会福利政 策化一直是备受争议的话题, 但从市场的角度来看, 更新政
策的社会福利化政策整合对于存量规划中的产权价格影响是 冊庸置疑的。若将土地及其资产的价值作为个人整体收人的 组成部分, 社会福利的提高无疑会降低其土地相关资产的财 富比重, 进而降低其稀缺性, 从而有助于促进存量规划中的 产权交易。

英国是较早践行城市更新的国家。城市更新作为适应社 会、经济和政治不同需求, 协调政府与更新市场关系的重要 政策工具, 其政策经历了较长的发展历程, 具有其自身的政 策制定逻辑与实践路径依赖, 尤其是英国政策的“实验性” 特质, 通常是源于其执政哲学 (philosophy) 的变革需要。 对市场经济体系内实施的英国城市更新政策进行研究和分析 仍是一个值得深人探讨的议题。以上分析和讨论有助于理解 当前英国城市更新政策的发展及其矛盾所在, 为提高我国存 量规划的市场性质认识以及相关工作的开展提供借鉴。

UPI

\section{参考文献}

[1] DCLG. Regeneration to enable growth: what government is doing[EB/OL]. London: DCLG, (2011) [2015-02-05]. https://www.gov.uk/search?q=Reg eneration+to+Enable+Growth\% $3 \mathrm{~A}+$ What + Government + is + doing\& filter organisations $\% 5 \mathrm{~B} \% 5 \mathrm{D}=$ department-for-communities-and-local-government.

[2] TALLON A. Urban regeneration in the UK[M]. 2th ed. London: Routledge, 2013.

[3] SMITH A. Large-scale events and sustainable urban regeneration: key principles for host cities[J]. Journal of Urban Regeneration and Renewal, 2007, 1: 178-190.

[4] SHAW K, ROBINSON F. UK urban regeneration policies in the early twenty-first century: continuity or change?[J]. Town Planning Review, 2010, 81: 123-149.

[5] LAWLESS P. Understanding the scale and nature of outcome change in arearegeneration programmes: evidence from the New Deal for Communities programme in England[J]. Environment and Planning C: Government and Policy, 2011, 29: 520-532.

[6] Centre for Cities. Cities Outlook 2012[R/OL]. London: Centre for Cities, (2012) [2015-02-20]. http://www.centreforcities.org/about/annual-reports/.

[7] MATTHEWS P. From area-based initiatives to strategic partnerships: have we lost the meaning of regeneration?[J]. Environment and Planning C: Government and Policy, 2012, 30: 147-161.

[8] DCLG. The credit crunch and regeneration: impact and implications[R/ OL]. London: DCLG, (2009) [2015-02-05]. https://www.gov.uk/search?q= The + Credit + Crunch + and + Regeneration $\% 3 \mathrm{~A}+$ Impact + and + Implications\&s how_organisations_filter=true.

[9] LEUNIG T, SWAFFIELD J. Cities unlimited: making urban regeneration work[R/OL]. London: Policy Exchange. [2015-02-18]. https:// policyexchange.org.uk/publication/cities-unlimited/.

[10] JONES P, EVANS J. Urban regeneration in the UK[M]. London: Sage, 2008: 31-32.

[11] Stationery Office. Localism Act 2011[EB/OL]. [2015-02-22]. http://www. legislation.gov.uk/ukpga/2011/20/pdfs/ukpga_20110020_en.pdf.

[12] DCLG. National Planning Policy Framework[EB/OL]. London: The National Archives, (2012) [2015-02-20]. https://www.gov.uk/government/ uploads/system/_uploads/attachment_data/file/6077/2116950.pdf.

[13] DCLG, DBIS, HCA. 2010 to 2015 government policy: Local Enterprise Partnerships (LEPs) and enterprise zones[EB/OL]. [2015-02-23]. https:// www.gov.uk/government/publications/2010-to-2015-government-policy- 
local-enterprise-partnerships-leps-and-enterprise-zones.

[14] HM Government. Local growth: realising every place's potential[R/OL]. London: HMSO, (2010) [2015-02-23]. https://www.gov.uk/government/ uploads/system/uploads/attachment_data/file/32076/cm7961-localgrowth-white-paper.pdf.

[15] Birmingham City Council. Birmingham city centre enterprise zone[EB/OL]. [2015-02-23]. https://www.birmingham.gov.uk/info/20139/support_for business/67/birmingham_city_centre_enterprise_zone.

[16] HM Governmnet. Birmingham enterprise zone[EB/OL]. [2015-02-23]. http://enterprisezones.communities.gov.uk/enterprise-zone-finder/ birmingham-enterprise-zone/\#!prettyPhoto.

[17] DCLG. 2010 to 2015 government policy: Local Enterprise Partnerships (LEPs) and enterprise zones[EB/OL]. [2015-02-26]. https://www.gov.uk/ government/publications/2010-to-2015-government-policy-local-enterprisepartnerships-leps-and-enterprise-zones.

[18] Cabinet Office. 2010 to 2015 government policy: City Deals and Growth Deals[EB/OL]. [2015-02-26]. https://www.gov.uk/government/ publications/2010-to-2015-government-policy-city-deals-and-growth-deals/.

[19] HM Governmnet. Unlocking growth in cities: city deals - wave 1[EB/OL]. [2015-02-26]. https://www.gov.uk/government/uploads/system/uploads/ attachment_data/file/221009/Guide-to-City-Deals-wave-1.pdf.

[20] DCLG. 2010 to 2015 government policy: Regional Growth Fund[EB/OL]. [2015-03-05]. https://www.gov.uk/government/publications/2010-to-2015government-policy-regional-growth-fund.

[21] DBIS. Regional Growth Fund: impact and economic evaluation options[R/ OL]. [2015-03-05]. https://www.gov.uk/government/publications/regionalgrowth-fund-impact-and-economic-evaluation-options.

[22] DCLG. 2010 to 2015 government policy: localism[EB/OL]. [2015-03-08]. https://www.gov.uk/government/publications/2010-to-2015-governmentpolicy-localism/2010-to-2015-government-policy-localism.

[23] DCLG. Neighbourhood Planning[EB/OL]. [2015-03-08]. https://www.gov. uk/government/uploads/system/uploads/attachment_data/file/229749/ Neighbourhood_planning.pdf.

[24] DCLG. Planning system[EB/OL]. [2015-03-08]. https://www.gov.uk/ government/publications/2010-to-2015-government-policy-planning-system/ planning-system.

[25] DCLG. 2010 to 2015 government policy: planning reform[EB/OL]. [201503-08]. https://www.gov.uk/government/publications/2010-to-2015government-policy-planning-reform/2010-to-2015-government-policyplanning-reform.

[26] 杨东峰. 重构可持续的空间规划体系- 2010 年以来英国规划创新与 争议 [J]. 城市规划, 2016, 40(8): 91-99.

[27] The UK Government. Housing and Planning Act 2016[EB/OL]. [2015-0308]. http://services.parliament.uk/bills/2015-16/housingandplanning.html.

[28] The UK Government. Neighbourhood Planning Bill[EB/OL]. [2015-03-08]. https://www.publications.parliament.uk/pa/bills/ lbill/2016-2017/0106/17106.pdf.

[29] Conervatives. Open Source Planning[EB/OL]. [2015-03-10]. http://www. conservatives.com/News/News_stories/2010/02/New_ homes_and_jobs_ through_Open_Source_Planning.asp.

[30] HAMBLETON R. A Jekyll and Hyde localism bill?[J]. Town \& Country Planning Association, 2011, 80: 15-17.

[31] Department for Transport. Growing places fund[EB/OL]. [2015-03-15]. https://www.gov.uk/government/uploads/system/uploads/attachment_ data/file/4922/f0008250.pdf.

[32] DCLG. The growing places fund[EB/OL]. [2015-03-15]. https://www.gov. uk/government/collections/the-growing-places-fund.

[33] DWP, HM Treasury. 2010 to 2015 government policy: employment[EB/ OL]. [2015-03-15]. https://www.gov.uk/government/publications/2010to-2015-government-policy-employment/2010-to-2015-government-policyemployment.
[34] DCLG. 2010 to 2015 government policy: support for families[EB/OL]. [2015-03-15]. https://www.gov.uk/government/publications/2010-to-2015 government-policy-support-for-families/2010-to-2015-government-policysupport-for-families.

[35] 巴里・卡林沃思, 艾森特・纳丁. 英国城乡规划 [M] 陈闽齐, 等, 译、 东南大学出版社, 2011: 2-14

[36] 赵燕菁. 存量规划: 理论与实践 [J]. 北京规划建设, 2014(4): 153-156.

[37] 田莉, 姚之浩, 郭旭, 等。基于产权重构的土地再开发——新型城镇化 背景下的地方实践与启示 [J]. 城市规划, 2015, 39(1): 22-29.

(本文编辑：秦潇雨) 